demonstrate thyroid-stimulating activity in pituitary extracts from animals ranging over the entire verte. brate series, although at considerably lower concentrations than are found in mammals. Certain features of these results, however, present difficulties of interpretation. For example, a large part of the activity is heat-stable, while mammalian thyroid-stimulating hormone is markedly heat-labile. Moreover, measurable activity is obtained from the neural lobe, even in the mammal, although there is every reason for regarding thyroid-stimulating hormone as a product of the adenohypophysis. The significance of these facts is bound to remain obscure until we are better informed of the chemical nature of thyroid-stimulating hormone; but in the meantime it is necessary to remember that glandular extracts may contain a large number of contaminants, hormonal and otherwise, which are likely to interfere with responses, and which cannot be adequately controlled by injections of indifferent tissues such as brain or muscle. It is possible, too, that foreign pituitary material may set up interfering stress responses, while it is known that the relative thyroid-stimulating potency of extracts from different species varies according to the choice of the assay animal.

These considerations combine to make it impossible to deeide whether the apparently low concentrations of the hormone in extracts of pituitaries of the lower vertebrates reflect quantitative or qualitative differences. It may be, however, that the thyroid-stimulating hormone molecule has been subjected to biochemical evolution, but has yet retained sufficient community of chemical structure throughout the vertebrates to allow pituitary extracts from a wide range of donors to stimulate the thyroids of a wide range of recipients.

Further aspects of endocrine evolution were brought to light in Dr. J. G. Phillips's discussion of the adrenal gland. There is much variation in the gross appearance of this organ, and in the degree of association of its two components, the chromaffin and the adrenocortical tissue, but these variations, characteristic of each of the main vertebrate groups, mask a remarkable constancy in the properties of its secretory cells. This is well illustrated by the steroid hormones of the adrenocortical tissue, which appear to be chemically identical throughout the vertebrate series, and which are involved in homeostatic mechanisms contributing in one way or another to ensure a constancy of the internal medium. Nevertheless, this fundamental uniformity has not prevented the establishment of a wide degree of functional adaptive radiation. In the sphere of water and salt metabolism, for example, these hormones influence tissues such as the nephron, the gills of fish, and the skin and bladder of frogs, all of which share a common capacity for the transcellular conduction of electrolytes and water, and which react to adrenocortical hormones in a manner determined by the nature of the environ- mental hazards to which the particular species is exposed. Thus, marine fish are faced with the problem of retaining water and excreting excess salts, while the converse situation confronts freshwater species, and these hormones, although not the only factors involved, contribute to the necessary physiological adaptations by their action on the kidneys and the gills. In sea-water they promote the excretion of excess electrolytes through the gills, and the maximal re-absorption of water in the kidneys, while in fresh water they promote the excretion of large volumes of dilute urine, accompanied by salt retention.

It is evident that one important factor in the evolution of endocrine systems is the possibility of change in the character of the target organs, and Dr. Phillips illustrated this by reference to recent work on the remarkable ability of marine birds to survive for long periods the ingestion of fluids which have an ionic concentration many times higher than that of their body fluids. This ability depends on the nasal glands, situated above the eyes. Following the ingestion of sea-water, these glands are activated, and, as a result of their remarkable concentrating ability, the bird excretes the excess salt through the nasal gland without commensurate loss of water. The action of the adrenocortical hormones is one of the factors involved in this response, and there is evidence that, with the hormones of the neural lobe of the pituitary, they arrest the excretion of the excess salt through the kidney; this is then followed by a shift to the physiologically more economical method of excretion through the nasal glands. There is good evidence that the latter are also dependent on the nervous system, but at present it is not possible to judge the relative importance of the two forms of control. It is clear, however, that the action of the adrenocortical hormones on the nasal glands is closely analogous with their action on the gills of marine fish, for in both cases they serve to promote the excretion from the body of excess salt without undue loss of water.

The final paper was given by Dr. D. B. Carlisle, who reviewed some problems of crustacean endocrinology, and this was followed by a lively discussion which ranged over such diverse problems as sexreversal in molluscs, the function of indole derivatives in crustaceans, the influence of ciliary feeding in the evolution of the thyroid gland, and the possible role of adrenocortical tissue in the metamorphosis of lampreys. The session as a whole must have done much to reassure those who fear that endocrinology, with its para-medical background and its esoteric terminology, is too specialized for comprehension by the general biologist, and it amply demonstrated how widespread are the biological problems which are being illuminated by present developments in the comparative study of endocrine mechanisms.

E. J. W. BARRINGtoN

\title{
OBITUARIES
}

Prof. H. P. Robertson

Prof. H. P. Robertson, who contributed to the theories of relativity and cosmology, and was a member of many Government scientific boards in the United States, died on August 26 as a result of injuries sustained in a motor-car accident. His death takes from many people throughout the world a sensitive, gay and ever-helpful friend as well as an experienced and wise counsellor.

He was born in Hoquiam, Washington, on January 27,1903 , and received his bachelor's and master's degrees in 1922 and 1923, respectively, from the University of Washington, where he was introduced to the Einstein theory of relativity by E. T. Bell. 
He obtained the Ph.D. degree from the California Institute of Technology in 1925 and then spent two years in Germany as a National Research Fellow at Göttingen and Munich. He joined the Mathematics Department of the California Institute of Technology as an assistant professor of mathematics for the period 1927-29.

During 1929-47 he was at Princeton University, occupying successively the posts of assistant professor, associate professor and professor of mathematical physics. In 1947 he returned to the California Institute of Technology as professor of mathematical physics, a post he held until his death.

Although Robertson devoted most of his scientific efforts to the general theory of relativity and to its application to cosmological problems, he was interested in the foundation of physical theories and the application of various branches of abstract mathematics to physical problems. His excellent translation of Herman Weyl's The Theory of Groups and Quantum Mechanics, which he completed in 1931, demonstrates his profound knowledge of the theory of groups, quantum mechanics and the relationship existing between these two subjects.

He was a master in applying the theory of groups of motion of Riemannian spaces to problems in relativity. His 1933 paper entitled "Relativistic Cosmology", which appeared in the Reviews of Modern Physics, illustrates his use of the technique. In this classic paper he summarizes his own basic work and that of others on the consequences of the symmetry assumptions made in relativistic cosmology and relates these to the astronomical observations. He afterwards studied the implications of the symmetry assumptions alone, divorcing these from the Einstein field equations. The latter work was stimulated by the lively controversy over kinematical relativity, in which he and E. A. Milne engaged, and appeared in three papers and in the Astrophysical Journal $(1935,1936)$ entitled "Kinematies and World Structure".

Robertson's contributions to relativity should not be measured only by his own papers. He engaged in extensive discussions with, and participated in the work of, others. His aid is acknowledged by many authors; in particular, he played an important part in the work of Einstein. Infeld and Hoffmann on the equations of motion of singularities in the gravitational fields and published his solution of the equations for two bodies with comparable masses obtained by these authors.

In 1939 Robertson responded to a call from his friend and mentor, R. C. Tolman, and began his work on scientific problems important to United States military agencies. He stopped his intensive work in relativity, which was just coming to fruition, and answered to the demands made on him with characteristic vigour. $\mathrm{He}$ quickly produced a scholarly review of work in terminal ballistics and made contributions to this field. He took an active part in organizing the group that became Division II of the National Defense Research Committee and in directing the early work of this group.

$\mathrm{He}$ served with the National Defense Research Committee from 1940 until 1943 and as scientific liaison officer, London Mission, Office of Scientific Research and Development, during 1943-46. From 1944 until 1947 he was an expert consultant to the Office of the Secretary of War. In 1945 he was chief of the Scientific Intelligence Advisory Section of Supreme Headquarters, Allied Expeditionary Force in France. For his war service he received the United States Medal of Merit.

In 1950 he was called back to Washington and served for two years as deputy director and research director of the Weapons Systems Evaluation Group of the Department of Defense until 1952. During 1954-56 he was the scientific adviser to General A. M. Gruenther, the then Supreme Allied Commander in Europe. For four years beginning in 1956 he was member at large and chairman of the Defense Science Board. He was also a member of the President's Scientific Advisory Committee.

In addition to belonging to a number of scientific societies, Robertson was a member of the U.S. National Academy of Sciences, of which he was foreign secretary from 1958 until his death.

Although Robertson never lost his interest in working in the theory of relativity and in teaching this subject, his many Washington duties to which he gave himself unstintingly made it impossible for him to do more than publish a few papers after the Second World War. In some of these he again reviewed the theoretical and observational state of the theory of cosmology. He was much interested in the possibilities of using satellites for experimental tests of theories of gravitation and took part in organizing, and was chairman of, a conference on this subject in July last at Stanford University.

This review of some of Prof. Robertson's achievements and activities must of necessity omit much that should be said about him. Suffice it to say that he made his mark in science, in service to his country, and in the hearts of the many people from all walks of life who were privileged to know him.

A. H. TAUB

\section{Mr. Lewis Eynon}

THE news of the death on October 18 at the home of his son at Stoke Bishop, Bristol, of Lewis Eynon will sadden his friends in many countries. The sugar industry has lost a most experienced analyst, who further had done so much to help the analytical profession. Eynon was born in 1878 at Stoke Newington and was educated at the City of London School. On leaving there he became a student at Finsbury Technical College during 1895-99 under Prof. Meldola. He was then appointed a chemist to the Beetroot Sugar Association. Another Finsbury student, J. H. Lane, was also there with him, and the two became partners in 1910 as consulting chemists. Having acquired the laboratories from the Sugar Association of London, as it had then become, and also the business of the analysis of its sugar samples, they had spare time which they used for research on sugar, chiefly on improvement of methods of sugar analysis. Their long search for a sensitive internal indicator for use with Fehling's solution for testing reducing sugars eventually led them to methylene blue. The result was the Land and Eynon method which has become well known throughout the sugar world. It has eventually been accepted as an official method by many countries and also by the International Commission.

Eynon obtained many qualifications and held many important offices arnong the various professional bodies to which he belonged. In 1900 he gained the associateship of the Royal Institute of Chemistry and was elected to the fellowship in 1903. A year later he graduated B.Sc. at the University of London with honours in chemistry. For many of the years between 